\title{
Role of atrial contraction and synchrony of ventricular contraction in the optimisation of ventriculoarterial coupling in humans
}

Kazuhiro Yamamoto, Kazuhisa Kodama, Tohru Masuyama, Atsushi Hirayama, Shinsuke Nanto, Masayoshi Mishima, Akira Kitabatake, Takenobu Kamada

\begin{abstract}
Objective-To examine the effects of pacing modes on the interaction between the left ventricle and arterial system in humans.

Design-The slope of the end systolic pressure-volume relation (end systolic elastance), effective arterial elastance, the ratio of effective arterial elastance to end systolic elastance, and mechanical energy efficiency were compared under different pacing modes (atrial, atrioven-
\end{abstract} tricular, and ventricular).

Patients-Nine male patients with sick sinus syndrome who had cardiac catheterisation for diagnosis and to see whether they needed a pacemaker.

Interventions-A conductance catheter with tip-manometer was inserted into the left ventricle to obtain pressurevolume loops, and two pacing catheters were inserted into the right atrium and into the right ventricle respectively.

Results-End systolic elastance was lower in atrioventricular pacing than in atrial pacing, but effective arterial elastance was not significantly different. End systolic elastance was lower in ventricular pacing than in atrioventricular pacing, and effective arterial elastance was higher in ventricular pacing than in atrioventricular pacing. Consequently the ratio of effective arterial elastance to end systolic elastance was lowest in atrial pacing and highest in ventricular pacing, and mechanical energy efficiency was highest in atrial pacing and lowest in ventricular pacing.

Conclusions-Atrial contraction and synchronous ventricular contraction independently optimise ventriculoarterial coupling in terms of a transfer of energy. Thus atrial pacing gives the best ventriculo-arterial coupling among these pacing modes.

The First Department of Medicine, Osaka University School of Medicine, Osaka, Japan

T Masuyama

A Kitabatake

T Kamada

Correspondence to Dr Kazuhiro Yamamoto, The First Department of Medicine, Osaka University School of Medicine, $1-1-50$ Fukushima, Fukushima-ku, Osaka 553, Japan.

Accepted for publication 13 September 1991

Pacemaker implantation is now widely used to treat bradycardia. The synchrony of ventricular contraction during atrial pacing differs from that during atrioventricular and ventricular pacing. Atrioventricular pacing produces atrial contraction whereas ventricular pacing does not. Previous studies showed the benefits of physiological pacing over ventricular pacing in terms of haemodynamic function-that is, cardiac output, arterial pressure, etc. ${ }^{1-3}$ However, the interaction between the left ventricle and arterial system (ventriculoarterial coupling) has not yet been studied. The assessment of ventriculoarterial coupling is particularly important because the nature of the coupling of the left ventricle to the arterial system determines the efficiency of energy transfer to the circulation and is a major determinant of ventricular and circulatory performance. ${ }^{4-6}$

A conductance catheter with tip manometer ${ }^{7-9}$ can be used to obtain left ventricular pressure-volume loops on a beat-to-beat basis and to show the end systolic pressure-volume relation. On the pressure-volume diagram the slope of the end systolic pressure-volume relation (end systolic elastance) $)^{10-12}$ and effective arterial elastance $e^{1314}$ can be simultaneously determined to assess ventriculoarterial coupling. Furthermore, the pressure-volume diagram provides an estimate of mechanical energy efficiency-that is, the ratio between work area and the pressure-volume area, because the pressure-volume area is linearly related to ventricular oxygen consumption. ${ }^{4}$

We used a conductance catheter to assess the effect of pacing modes on the interaction between the left ventricle and arterial system.

\section{Patients and methods}

\section{PATIENTS}

We studied nine men (44-64 (mean 55)) with sick sinus syndrome. All of them had cardiac catheterisation for diagnosis and to decide whether they needed a pacemaker. Left ventriculography and coronary angiography showed no ventricular wall motion abnormality or coronary artery disease in any of the patients. None showed evidence of aortic or mitral regurgitation or left ventricular hypertrophy on the left ventriculogram and echocardiogram.

All patients gave informed consent to diagnostic catheterisation and participation in the study protocol. The protocol was approved by
PRESSURE AND VOLUME MEASUREMENT

A conductance catheter with a manometer at its tip was inserted into the left ventricle. This catheter was connected to a volumetric system (Model Sigma 5, Leycom, Oegstgeest, The Netherlands) to convert left ventricular conductance to left ventricular volume. The posi- 
tion of the catheter in the left ventricle was confirmed by the presence of a signal with a flat upper segment or identity of the phase of the signal among the segments. The catheter technique for measurement of left ventricular volume has been described in detail elsewhere..$^{7815}$ In brief, the instantaneous left ventricular volume, $V(t)$, was obtained by the Sigma 5 as:

$$
V(t)=(1 / a)\left(L^{2} / B\right) G(t)-V c
$$

where $a$ is a dimensionless constant, $L$ is an interelectrode distance, $B$ is the specific conductivity of blood measured by a calibrating cuvette, and $G(t)$ is the sum of the segmental conductance measured between the five pairs of adjacent electrodes. $\mathrm{Vc}$ is the correction volume for the parallel conductance.

The so-called dilution method was used to obtain the correction volume, Vc. A bolus of hypertonic salt solution $(6 \% \mathrm{NaCl})$ of $10 \mathrm{ml}$ was injected into pulmonary artery through a balloon-tipped flotation thermodilution catheter. As the salt solution mixed with blood in the left ventricle its conductivity (B in equation (1)) increased, causing the overall conductance signal $\mathrm{G}(\mathrm{t})$ to increase while the parallel component remained constant. When measured end systolic volume was plotted as a function of measured end diastolic volume during the mixing of the bolus and linear regression analysis was applied to the relation between measured end systolic volume and measured end diastolic volume data points, the intersection point between the regression line and the line of identity was Vc, the correction volume. $^{7}$

To determine a in equation (1) the stroke volume was simultaneously measured by the thermodilution method and by a conductance catheter. ${ }^{15}$

Actual stroke volume $=$

$(1 / a)=$

$$
(1 / a)\left(L^{2} / B\right)(G(e d)-G(e s))
$$

actual stroke volume $/\left(\mathrm{L}^{2} / \mathrm{B}\right) /(\mathrm{G}(\mathrm{ed})-\mathrm{G}(\mathrm{es}))$

where the actual stroke volume is the stroke volume measured by the thermodilution method, G(ed) is the sum of the segmental end diastolic conductance, and $G(e s)$ is the sum of the segmental end systolic conductance.

Good correlations between left ventricular volumes measured by the conductance catheter and by other methods have been shown both by us ${ }^{16}$ and others. ${ }^{7118}$ The signals of left ventricular volume and pressure were sampled every $5 \mathrm{~ms}$ and analysed on a personal computer (NEC 9800 (NEC, Japan)).

EVALUATION OF THE END SYSTOLIC PRESSUREVOLUME RELATION

To measure the end systolic pressure-volume relation, the inferior vena cava was obstructed with the Fogarty catheter to reduce peak systolic pressure by $15-40 \%$. A maximum pressure-volume ratio point-that is, the peak value of the ratio of left ventricular pressure to left ventricular volume within cardiac cyclewas calculated over eight seconds during occlusion of the inferior vena cava. Linear regression analysis of these points was used to determine the end systolic pressure-volume relation, ${ }^{19}$ and end systolic elastance was used as an index of cardiac contractility. ${ }^{10-12}$

EVALUATION OF EFFECTIVE ARTERIAL ELASTANCE Effective arterial elastance can be determined in the pressure-volume diagram as the ratio of end systolic pressure to stroke volume ${ }^{1314}$ :

$$
\mathrm{Ea}=\mathrm{Pes} / \mathrm{SV}=(\mathbf{R c}+\mathbf{R}) / \mathrm{T}
$$

where $\mathrm{Ea}$ is the effective arterial elastance, Pes the left ventricular end systolic pressure, SV the stroke volume, $\mathrm{Rc}$ the characteristic impedance, $R$ the arterial resistance, and $T$ the duration of one cardiac cycle.

In this study, heart rate was fixed at 90 beats per minute to keep $\mathrm{T}$ in equation (2) constant; therefore, effective arterial elastance changed in parallel with the total arterial elastance.

\section{EVALUATION OF MECHANICAL ENERGY}

\section{EFFICIENCY}

Mechanical energy efficiency was determined as the ratio of external work to pressurevolume area by the following equation, ${ }^{45}$

Mechanical energy efficiency = external work/ pressure-volume area

The pressure-volume area, which was determined as the area surrounded by the line of the end systolic pressure-volume relation, the end diastolic pressure-volume curve, and the systolic segment of the pressure-volume trajectory, represents the total mechanical energy of the ejecting contraction. ${ }^{4}$ External work was measured as the area enclosed by a pressure-volume loop.

\section{PACING STUDY}

Two bipolar pacing catheters were introduced through the femoral vein and positioned in the right atrial appendage and the right ventricular apex, respectively. Pressure-volume loops and end systolic pressure-volume relations were obtained during atrial, atrioventricular, and ventricular pacing with a constant heart rate of 90 beats per minute when the inferior vena cava was occluded. The pacing modes were changed in a random order. Data were recorded five minutes after the pacing mode was changed. During ventricular pacing the atrium was paced $50 \mathrm{~ms}$ after the ventricle to exclude the contribution of random atrial contraction to left ventricular filling. During atrioventricular pacing the atrioventricular delay was $150 \mathrm{~ms}$.

\section{STATISTICAL ANALYSIS}

Values are expressed as mean (SD). The statistical significance of differences in the indices among pacing modes was tested by an analysis of variance (ANOVA) and Scheffe's F test. Results were regarded as significant when $\mathrm{p}<0.05$.

\section{Results}

Figure 1 shows representative pressurevolume loops for each pacing mode. Panel A shows pressure-volume loops and end systolic 
Figure 1 Representative pressure-volume loops obtained at atrial pacing (A), atrioventricular pacing $(B)$, and ventricular pacing $(C)$. End systolic elastance (Ees) and mechanical energy efficiency (Eff) were lower and effective arterial elastance (Ea) was higher during ventricular pacing than during atrioventricular pacing. Ees and Eff were lower during atrioventricular pacing than during atrial pacing.

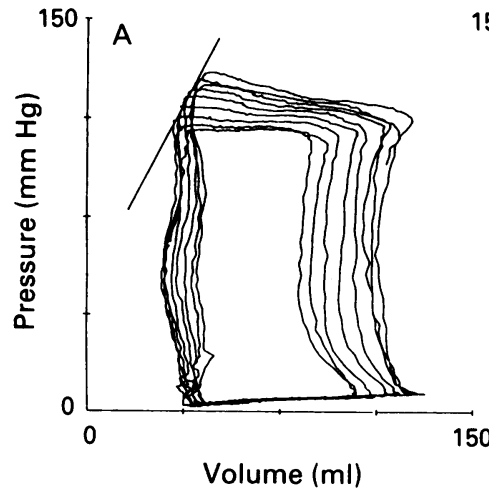
Ees $=2.0 \mathrm{~mm} \mathrm{Hg} / \mathrm{ml}$
$E a=1.6 \mathrm{~mm} \mathrm{Hg} / \mathrm{ml}$
Eff $=63 \%$

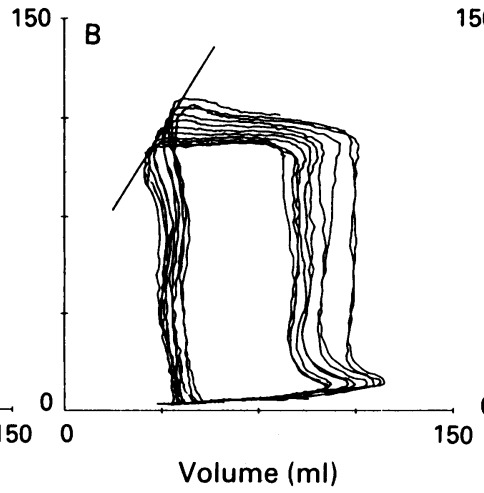

Ees $=1.6 \mathrm{~mm} \mathrm{Hg} / \mathrm{ml}$ $\mathrm{Ea}=1.7 \mathrm{~mm} \mathrm{Hg} / \mathrm{ml}$ $\mathrm{Eff}=59 \%$

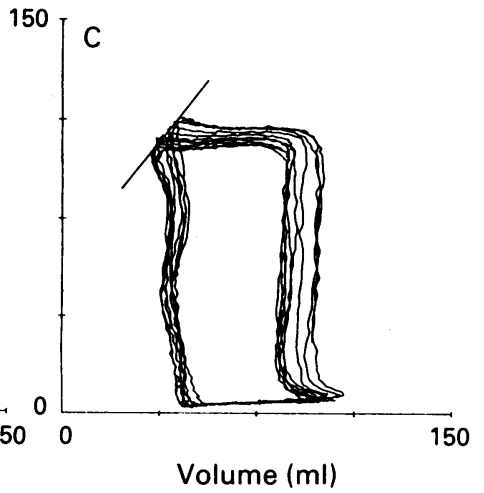

Ees $=1.2 \mathrm{~mm} \mathrm{Hg} / \mathrm{m}$ $\mathrm{Ea}=2.1 \mathrm{~mm} \mathrm{Hg} / \mathrm{ml}$ $\mathrm{Eff}=51 \%$ pressure-volume relations obtained during occlusion of the inferior vena cava and atrial pacing. End systolic elastance and mechanical energy efficiency were lower during atrioventricular pacing than during atrial pacing (B). End systolic elastance and mechanical energy efficiency were lower and effective arterial elastance was higher in ventricular pacing than in atrioventricular pacing $(\mathrm{C})$.
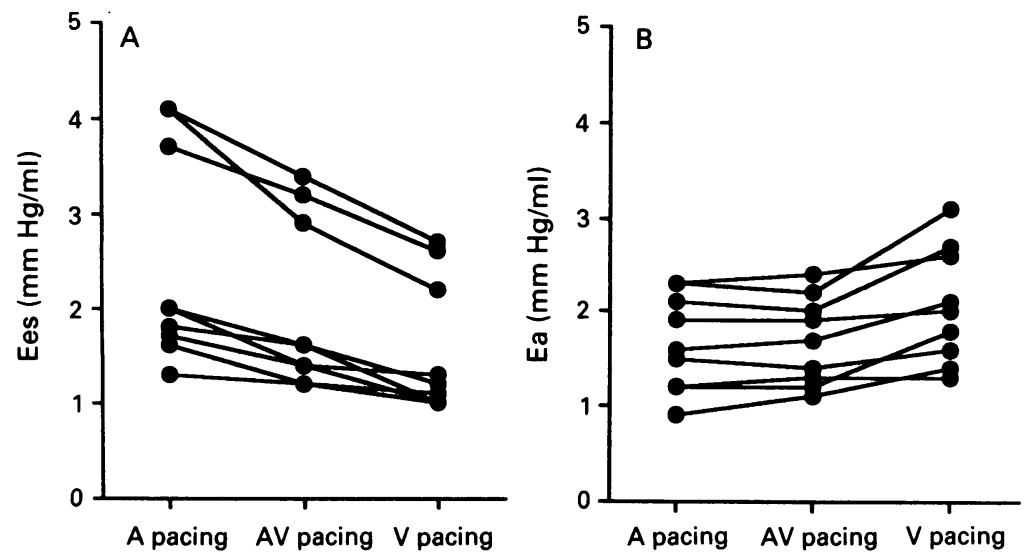

Figure 2 ( $A$ ) Changes in end systolic elastance (Ees) during atrial $(A)$ pacing, atrioventricular $(A V)$ pacing, and ventricular $(V)$ pacing. Ees during atrial pacing was significantly higher than during atrioventricular pacing $(p<0.01)$. Ees during atrioventricular pacing was higher than during ventricular pacing $(p<0.05)$.

(B) Changes in effective arterial elastance (Ea) during atrial pacing, atrioventricular pacing and ventricular pacing. Ea was similar during atrial pacing and atrioventricular pacing. However, Ea was higher during ventricular pacing than during atrioventricular pacing $(p<0.01)$

Haemodynamic variables (mean (SD)) in the three pacing modes

\begin{tabular}{lccc}
\hline Variable & Atrial pacing & AV pacing & $\begin{array}{l}\text { Ventricular } \\
\text { pacing }\end{array}$ \\
\hline LVESVI $\left(\mathrm{ml} / \mathrm{m}^{2}\right)$ & $24(7)$ & $23(8)$ & $23(7)$ \\
LVEDVI $\left(\mathrm{ml}^{2} / \mathrm{m}^{2}\right)$ & $69(11)$ & $66(10)$ & $55(11)^{\star \star \dagger \dagger}$ \\
SVI $\left(\mathrm{ml} / \mathrm{m}^{2}\right)$ & $46(8)$ & $43(5)$ & $32(6)^{\star \star \dagger}$ \\
LVESP $(\mathrm{mm} \mathrm{Hg})$ & $132(27)$ & $130(25)$ & $113(17)^{\star \star \dagger \dagger}$ \\
Ees $(\mathrm{mm} \mathrm{Hg} / \mathrm{ml})$ & $2 \cdot 5(1 \cdot 1)$ & $2 \cdot 0(0 \cdot 9)^{\star \star}$ & $1 \cdot 6(0 \cdot 7)^{\star \star \dagger}$ \\
Ea $(\mathrm{mm} \mathrm{Hg} / \mathrm{ml})$ & $1 \cdot 7(0 \cdot 5)$ & $1 \cdot 7(0 \cdot 5)$ & $2 \cdot 1(0 \cdot 6)^{\star \star \dagger \dagger}$ \\
Ea/Ees & $0 \cdot 72(0 \cdot 18)$ & $0.92(0 \cdot 22)^{\star}$ & $1 \cdot 41(0 \cdot 29)^{\star \star \dagger \dagger}$ \\
Eff $(\%)$ & $68(8)$ & $63(9)^{\star \star}$ & $56(8)^{\star \star \dagger \dagger}$
\end{tabular}

${ }^{\star} \mathrm{p}<0.05$ and ${ }^{\star \star} \mathrm{p}<0.01$ versus atrial pacing; $\mathrm{tp}<0.05$ and $+t_{\mathrm{p}}<0.01$ versus atrioventricular pacing.

AV, atrioventricular; Ea, effective arterial elastance; Ees, end systolic elastance; Eff, mechanical energy efficiency; LVEDVI, left ventricular end diastolic volume index; LVESP, left ventricular end systolic pressure; LVESVI, left ventricular end systolic volume index; SVI, stroke volume index.

\section{LEFT VENTRICULAR PRESSURE AND VOLUME} CHANGES

Left ventricular volume index and pressure were not significantly different during atrial pacing and during atrioventricular pacing. Left ventricular end diastolic volume index and left ventricular end systolic pressure were smaller during ventricular pacing than during atrioventricular pacing $(p<0.01)$. Left ventricular end systolic volume indices during these two pacing modes were not significantly different. Consequently, stroke volume index was significantly smaller during ventricular pacing than during atrioventricular pacing (table).

CHANGES IN VENTRICULOARTERIAL COUPLING AND MECHANICAL ENERGY EFFICIENCY

End systolic elastance was $16 \%$ lower during atrioventricular pacing than during atrial pacing (fig 2A) ( $p<0.01$ ) and effective arterial elastance was similar during both modes (fig 2B). Therefore, the mean ratio of effective arterial elastance to end systolic elastance was greater (fig 3A) and mechanical energy efficiency was smaller (fig 3B) during atrioventricular pacing than during atrial pacing.

During ventricular pacing end systolic elastance was lower ( $p<0.05)$ (fig 2A) and effective arterial elastance was $23 \%$ higher $(p<0.01)$ than during atrioventricular pacing (fig 2B). Thus the mean ratio of effective arterial elastance to end systolic elastance was greater (fig 3A) and mechanical energy efficiency was less (fig 3B) during ventricular pacing than during atrioventricular pacing.

\section{Discussion}

The effects of pacing modes-that is, atrial, atrioventricular, and ventricular pacing-on the interaction of the left ventricle and arterial system were assessed by the measurement of end systolic elastance and effective arterial elastance. Both atrial contraction and synchrony of ventricular contraction were important in the optimisation of ventriculoarterial coupling.

\section{SYNCHRONY OF LEFT VENTRICULAR}

\section{CONTRACTION}

There was no significant difference in left ventricular volume and pressure between atrial 

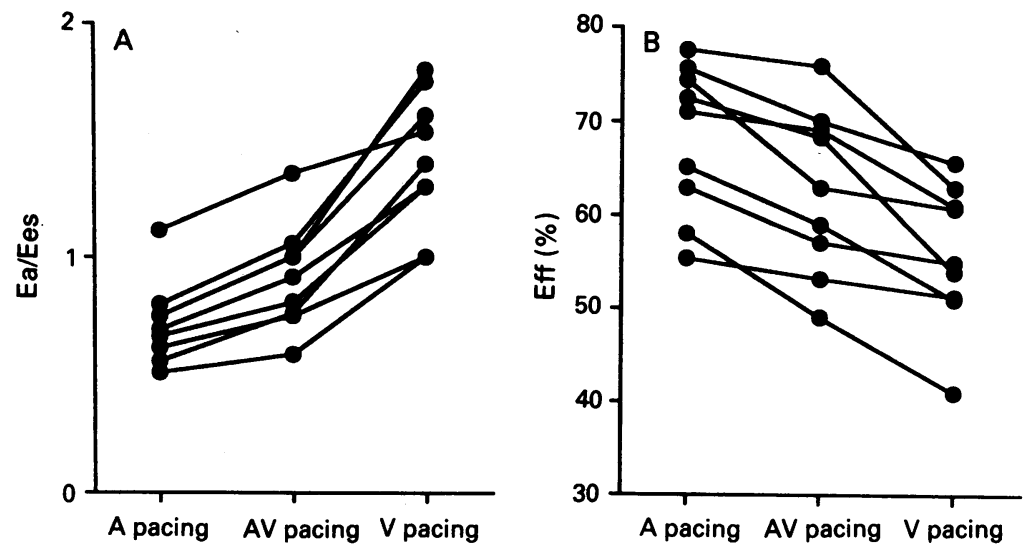

Figure 3 (A) Changes in Ea/Ees between atrial $(A)$ pacing, atrioventricular $(A V)$ pacing, and ventricular $(V)$ pacing. This ratio was lowest during atrial pacing and highest during ventricular pacing. (B) Changes in Eff during atrial pacing,

atrioventricular pacing, and ventricular pacing. Eff was highest during atrial pacing and lowest during ventricular pacing. See legend to fig 1 for abbreviations.

pacing and atrioventricular pacing. Therefore there was no significant difference in effective arterial elastance between these two pacing modes. End systolic elastance was lower in atrioventricular pacing than in atrial pacing. The reduction of end systolic elastance may be due to dyssynchronous ventricular contraction, because the mode of ventricular contractionthat is, synchronous or dyssynchronous-is the most important difference between these pacing modes. Badke et al reported that ventricular pacing promoted dyssynchronous ventricular contraction with reciprocal interactions between the early and late shortening areas. ${ }^{20} \mathrm{At}$ end systole those portions of the left ventricle that were activated first lengthen (whereas in the most recently activated area they shorten) and thus do not contribute to the generation of end systolic left ventricular pressure. There are several reports that areas of the left ventricle that are activated early bulge paradoxically in late systolic phase during dyssynchronous left ventricular contraction. ${ }^{21-23}$ Furthermore, Rosenqvist et al showed that abnormal ventricular activation-that is, dyssynchronous ventricular contraction-results in a significant deterioration in regional left ventricular systolic performance in humans. ${ }^{24}$ Burkhoff et al showed that pacing from different ventricular sites that changed the degree of dyssynchrony of ventricular contraction resulted in different intensities of ventricular performance. ${ }^{25}$ Thus dyssynchronous ventricular contraction may well be responsible for the reduced cardiac contractility during atrioventricular pacing.

\section{ATRIAL CONTRACTION}

Left ventricular end systolic pressure was lower during ventricular pacing than during atrioventricular pacing. In addition, without atrial contraction left ventricular end diastolic volume and stroke volume also decreased. Therefore, effective arterial elastance increased during ventricular pacing, as it did in an earlier study in dogs. ${ }^{26}$ Sympathetic stimulation, which is accompanied by a reduction of stroke volume, may be partly responsible for the increase in effective arterial elastance.
End systolic elastance was lower during ventricular pacing than during atrioventricular pacing (fig 2A). The lack of atrial contraction during ventricular pacing reduced the left ventricular end diastolic volume and changed the filling pattern. ${ }^{27}$ In earlier studies end systolic elastance was insentitive to changes of load. ${ }^{1028}$ However, a rapid increase in left ventricular volume in late diastole reduced left ventricular end systolic volume and increased left ventricular end systolic pressure. ${ }^{2930}$ This strongly suggests that cardiac contractility is increased by a rapid increase in left ventricular volume during late diastole. In ventricular pacing, filling occurs mainly in early diastole and little filling is seen in late diastole. In contrast, early diastolic filling is equal to or even less in atrioventricular pacing than in ventricular pacing, and during atrioventricular pacing late diastolic filling is much greater, producing a rapid increase in left ventricular volume. ${ }^{27}$ Thus the reduction of cardiac contractility in ventricular pacing may be explained by the difference in the filling pattern.

\section{VENTRICULOARTERIAL COUPLING AND} MECHANICAL ENERGY EFFICIENCY

The ratio of effective arterial elastance to end systolic elastance, the index of ventriculoarterial coupling, was lowest during atrial pacing and was highest during ventricular pacing. As a result, mechanical energy efficiency was highest in atrial pacing and lowest in ventricular pacing.

Earlier studies showed that the pressurevolume area represents the total mechanical energy generated by ventricular contraction. ${ }^{45}$ The efficiency of energy transfer from ventricular oxygen consumption to external work can be divided into two steps: the efficiency of energy transfer from ventricular oxygen consumption to the pressure-volume area and the efficiency of energy transfer from pressurevolume area to external work. ${ }^{31} 32$ The second step represents mechanical energy efficiency and we found that the efficiency of the second step was reduced by dyssynchrony of ventricular contraction and absence of atrial contraction. These results suggest that dyssynchronous ventricular contraction and absent atrial contraction waste energy and produce an energetically poor coupling between the left ventricle and the arterial system. We did not measure ventricular oxygen consumption so the effect of dyssynchronous ventricular contraction or absence of atrial contraction on the first step of energy transfer is unknown.

\section{STUDY LIMITATION}

The study population was small. The trends shown by the results were so clear, however, that we believe the conclusion of this study will not be affected by increasing the sample size.

Secondly, the end systolic pressure-volume relation in dogs was non-linear. ${ }^{33-35}$ None the less, Kass et al and Little et al reported that end systolic elastance did approximate to a straight line over a limited load range and that this could be used to assess the inotropic state..$^{36}$ 
We used a linear approximation of the end systolic pressure-volume relation to determine end systolic elastance in this study.

Thirdly, Boltwood et al reported difficulties in measuring "absolute" left ventricular volume by a conductance catheter.$^{38}$ But they also said that their data did not exclude the possibility that a conductance catheter can give a useful measurement of "relative" left ventricular volume over a range of haemodynamic states. Furthermore, the reliability of the measurement of left ventricular volume and of the end systolic pressure-volume relation by the conductance catheter has been validated by several groups, ${ }^{7940}$ and also by us. ${ }^{16}$ Burkhoff raised some questions about Boltwood et al's results. ${ }^{41}$ Thus we think that possible errors in the determination of left ventricular volumes with the conductance catheter are unlikely to affect the conclusion of our study.

Fourthly, atrioventricular delay can affect the results of this study. Iwase et al described the effects of atrioventricular delay on cardiac function. ${ }^{42}$ Nitsch et al and Videen $e t$ al, however, found that changes in the atrioventricular delay in patients without ventricular dysfunction had no significant haemodynamic effects. ${ }^{434}$ The haemodynamic effects of atrioventricular delay seem to depend on left ventricular function ${ }^{42} 45$ and the interatrial conduction delay. ${ }^{46}$ None of the patients we studied had left ventricular wall motion abnormality or coronary artery disease when they were examined by left ventriculography and coronary angiography. We examined a volume-time curve for the left atrium to ventricular sequence to determine the interatrial conduction delay. The interatrial conduction delay calculated as 150 ms minus the left atrium to ventricular sequence ranged from 76 to $97 \mathrm{~ms}$ (mean $86 \mathrm{~ms}$ ) in this study, and thus the effects of interindividual difference in the interatrial conduction delay on our results are likely to be small. Furthermore, the effects of atrioventricular delay were much smaller than those of the pacing mode. ${ }^{274245}$ However, in individuals with a long interatrial conduction delay the effects of interatrial conduction delay or atrioventricular delay would not be negligible.

Fifthly, we used atrial pacing $50 \mathrm{~ms}$ after the ventricular stimulation to exclude varying timing of atrial contraction during the cardiac cycle in ventricular pacing. Naito et al and Faerestrand et al showed that haemodynamic function was worse after ventricular pacing with retrograde ventriculoatrial conduction than after ventricular pacing without retrograde ventriculoatrial conduction or after atrial fibrillation with regular ventricular pacing. ${ }^{47}$ Naito et al suggested that this poor haemodynamic function when retrograde ventriculoatrial conduction was present might be explained by pulmonary venous regurgitation caused by atrial contraction during the ventricular ejection period. ${ }^{47}$ In addition, when the atrium contracts during the ventricular ejection period various reflex mechanisms such as atrial stretch receptors and baroreceptors might influence haemodynamic function including cardiac function. Thus the differen- ces that we found between atrioventricular and ventricular pacing may be partially attributable to the atrial pacing $50 \mathrm{~ms}$ after the ventricular stimulation.

Finally, we used effective arterial elastance as the index of afterload in this study and we did not take account of the influence of wave reflection in the arterial system on afterload because effective arterial elastance is developed on the basis of the three element Windkessel. Because we did not measure instantaneous arterial pressure we have no data on systemic arterial resistance and wave reflection. This precludes our assessing the relation between the changes in systemic arterial resistance and wave reflection and the changes in effective arterial elastance. However, Pepine et al and Murgo et al showed that peripheral resistance accounts for more than $90 \%$ of aortic input impedance and wave reflection for less than $5 \% .{ }^{49}{ }^{50}$ Burkhoff and his colleagues showed that the Windkessel model gave a reasonable representation of afterload. ${ }^{51}$ Sunagawa and his colleagues showed that most of the effects of afterload on stroke volume depended on peripheral resistance. ${ }^{52}$ They also showed that effective arterial elastance correlated linearly with the ratio of total resistance (the sum of the arterial resistance and characteristic impedance) to the duration of one cardiac cycle, ${ }^{53}$ and that the linear relation between end systolic pressure and stroke volume was seen under the same arterial impedance properties modelled in terms of a three element Windkessel. ${ }^{13}$ Thus we think that the changes in effective arterial elastance reflected the changes in afterload, and we used such changes to assess the changes in ventriculoarterial coupling.

\section{CLINICAL IMPLICATION}

Our study showed that end systolic elastance was lower during atrioventricular pacing than during atrial pacing and that end systolic elastance was lower and effective arterial elastance was higher during ventricular pacing than during atrioventricular pacing. Therefore mechanical energy efficiency was highest in atrial pacing and lowest in ventricular pacing. We conclude that dyssynchronous ventricular contraction promotes a reduction in cardiac contractility and modifies ventriculoarterial coupling to reduce mechanical energy efficiency. A lack of atrial contraction promotes a reduction in cardiac contractility and an increase in afterload, thus modifying ventriculoarterial coupling to reduce mechanical energy efficiency. These findings show that the pacing mode influences the interaction between the left ventricle and arterial system and that an atrial contraction and synchronous ventricular contraction are important in the optimisation of ventriculoarterial coupling. Rosenqvist et al found a significantly higher incidence of congestive heart failure and mortality in patients with ventricular pacing than in patients with atrial pacing. ${ }^{54}$ Alpert et al showed that the survival rate in patients with congestive heart failure was lower with ventricular pacing than with atrioventricular pacing. ${ }^{55}$ Our results suggest that these earlier findings may be partially 
explained by inappropriate ventriculoarterial coupling in patients with ventricular pacing.

Our results show that atrial pacing gave the best ventriculoarterial coupling and mechanical energy efficiency. In patients with ventricular dysfunction, optimisation of ventriculoarterial coupling is important because it is a determinant for external work. Burkhoff and Sagawa showed that stroke work is greatest when end systolic elastance equals effective arterial elastance. ${ }^{56}$ In patients with ischaemic heart disease optimisation of mechanical energy efficiency is important because blood supply is limited by coronary artery stenoses. Furthermore, dyssynchronous ventricular contraction had a deleterious effect on left ventricular relaxation..$^{57}$ Thus atrial pacing is especially suitable for patients with ventricular dysfunction and/or ischaemic heart disease. If possible, the atrioventricular delay should be prolonged in patients with atrioventricular pacing to obtain synchronous ventricular contraction.

This study also showed the advantage of assessing ventriculoarterial coupling in individual patients. For example, during ventricular pacing end systolic pressure was lowest, but "real afterload"- that is, effective arterial elastance-was highest because of the further reduction of stroke volume. During atrioventricular pacing left ventricular volume indices and pressure were not significantly different from those at atrial pacing; however, end systolic elastance-that is, the index of cardiac contractility - was smaller in atrioventricular pacing. Thus the assessment in terms of ventriculoarterial coupling gives more detailed information about the most suitable pacing mode in individual patients.

This work was presented in part at the 38th Annual Scientific Session of the American College of Cardiology, Anaheim, California, March 1989.

1 Reiter MJ, Hindman MC. Hemodynamic effects of acute atrioventricular sequential pacing in patients with left ventricular dysfunction. $A m J$ Cardiol 1982;49:687-92.

2 Kruse I, Arnman K, Conradson TB, Ryden L. A comparison of the acute and long-term hemodynamic effects of ventricular inhibited and atrial synchronous ventricular inhibited pacing. Circulation 1982;65:846-55.

3 Koretsune Y, Kodama K, Nanto S, et al. The effect of pacing mode on external work and myocardial oxygen consump-
tion. In: Steinbach $\mathrm{K}$, ed. Cardiac pacing. Darmstadt: Steinkopff Verlag, 1983:181-6.

4 Suga H. Total mechanical energy of a ventricle model and cardiac oxygen consumption. Am J Physiol 1979;236: H498-505.

5 Nozawa T, Yasumura Y, Futaki S, Tanaka N, Uenishi $M$ Suga $H$. Efficiency of energy transfer from pressureSuga $H$. Efficiency of energy transfer from pressure-
volume area to external mechanical work increases with volume area to external mechanical work increases with ventricle of the anesthetized closed-chest dog. Circulation ventricle of the an

6 Asanoi H, Sasayama S, Kameyama T. Ventriculoarterial coupling in normal and failing heart in humans. Circ Res 1989;65:483-93.

7 Baan J, Van der Velde ET, De Bruin HG, et al. Continuou measurement of left ventricular volume in animals and humans by conductance catheter. Circulation 1984;70: 812-23.

8 Baan J, Jong TTA, Kerkhof PLM, et al. Continuous stroke volume and cardiac output from intraventricular dimensions obtained with impedance catheter. Cardiovasc Res 1981;15:328-334

9 McKay RG, Spears JR, Aroesty JM, et al. Instantaneous measurement of left and right ventricular stroke volume and pressure-volume relationships with an impedance catheter. Circulation 1984;69:703-10.

10 Suga H, Sagawa K, Shoukas AA. Load independence of the instantaneous pressure-volume ratio of the canine left ventricle and the effects of epinephrine and heart rate on the ratio. Circ Res 1973;32:314-22.
11 Suga H, Sagawa K. Instantaneous pressure-volume relationships and their ratio in the excised, supported canine left ventricle. Circ Res 1974;35:117-26.

12 Grossman W, Braunwald E, Mann T, McL aurin LP, Green LH. Contractile state of the left ventricle in man as LH. Contractile state of the left ventricle in man as
evaluated from end-systolic pressure-volume relations. Circulation 1977;56:845-52.

13 Sunagawa K, Maughan WL, Burkhoff D. Left ventricular interaction with arterial load studied in isolated canine ventricle. Am J Physiol 1983;245:H773-80.

14 Sunagawa K, Maughan WL, Sagawa K. Optimal arteria resistance for the maximal stroke work studied in isolated canine left ventricle. Circ Res 1985;56:586-95.

15 Kass DA, Midel M, Graves W, Brinker JA, Maughan WL. Use of a conductance (volume) catheter and transien inferior vena caval occlusion for rapid determination of pressure-volume relationships in man. Cathet Cardiovasc Diagn 1988;15:192-202.

16 Yamamoto K, Kodama K, Masuyama $\mathrm{T}$, et al. Adverse effects of epinephrine in patients with advanced left ventricular dysfunction: analysis of ventriculo-arterial coupling. Int J Cardiol 1992;32:143-55.

17 Burkhoff D, Van der Velde E, Kass D, Baan J, Maughan WL Sagawa K. Accuracy of volume measurement by conductance catheter in isolated ejecting canine hearts. Circulatance catheter in iso

18 Applegate RJ, Cheng CP, Little WC. Simultaneous conductance catheter and dimension assessment of left ventricle volume in the intact animal. Circulation 1990;81:638-48.

19 Kono A, Maughan WL, Sunagawa K, Hamilton K, Sagawa $K$, Weisfeldt ML. The use of left ventricular end-ejection pressure and peak pressure in the estimation of the endsystolic pressure-volume relationship. Circulation 1984; 70:1057-65.

20 Badke FR, Boinay P, Covell JW. Effects of ventricular pacing on regional left ventricular performance in the dog. $\mathrm{Am} \mathrm{J}$ Physiol 1980;238:H858-67.

21 Hood WB Jr, Joison J, Abelmann WH, Norman JC Asynchronous contraction due to late systolic bulging at
left ventricular pacing sites. Am J Physiol 1969;217: 215-21.

22 Miyazawa K, Arai T, Shirato K, et al. Regional contraction patterns of the left ventricle during ventricular pacing. Tohoku J Exp Med 1977;122:167-74

23 Little WC, Reeves RC, Arciniegas J, Katholi RE, Rogers EW. Mechanism of abnormal interventricular septal motion during delayed left ventricular activation. Circulation 1982;65:1486-91.

24 Rosenqvist M, Isaaz K, Botvinick EH, et al. Relative importance of activation sequence compared to atrioventricular synchrony in left ventricular function. $\mathrm{Am}$ Cardiol 1991;67:148-56.

25 Burkhoff D, Oikawa RY, Sagawa K. Influence of pacing site on canine left ventricular contraction. $A m$ J Physiol 1986;251:H428-35.

26 Zhou JT, Yu GY. Hemodynamic findings during sinus rhythm, atrial and AV sequential pacing compared to

27 Masuyama T, Kodama K, Uematsu M, et al. Beneficial effects of atrioventricular sequential pacing on cardiac output and of atrioventricular sequential pacing on cardiac output and left ventricular filling assessed with pulsed

28 Sagawa K, Suga H, Shoukas AA, Bakalar KM. End-systolic pressure/volume ratio: a new index of ventricular contractility. Am J Cardiol 1977;40:748-53.

29 Kil PJM, Schiereck P. End-systolic pressure-volume relations of isolated ejecting rabbit left ventricles after quick diastolic volume changes. Cardiovasc Res 1985;19:782-92.

30 Van Hessen MWJ, Schiereck P, Stokhof AA, et al. Effect of timing of transient diastolic changes in ventricular fillin on LV performance in dogs. Am J Physiol 1989;257: H305-13.

31 Suga $H$, Hayashi T, Shirahata $M$. Ventricular systolic pressure-volume area as predictor of cardiac oxygen consumption. Am J Physiol 1981;240:H39-44.

32 Suga H, Hisano R, Goto T, Yamada O, Igarashi Y. Effect of positive inotropic agents on the relation between oxygen consumption and systolic pressure volume area in canine left ventricle. Circ Res 1983;53:306-18.

33 Burkhoff D, Sugiura S, Yue DT, Sagawa K. Contractilitydependent curvilinearity of end-systolic pressure-volume dependent curvilinearity of end-systolic pre

34 Freeman GL, Little WC, O'Rourke RA. The effect of vasoactive agents on the left ventricular end-systolic pressure-volume relation in closed-chest dogs. Circulation pressure-volume

35 Suga H, Yamada O, Goto Y, Igarashi Y. Peak isovolumic pressure-volume relation of puppy left ventricle. Am Physiol 1986;250:H167-72.

36 Kass DA, Beyar R, Landkford E, Heard M, Maughan WL Sagawa $K$. Influence of contractile state on curvilinearity of in situ end-systolic pressure-volume relations. Circulation 1989;79:167-78.

37 Little WC, Cheng C-P, Peterson T, Vinten-Johansen J. Response of the left ventricular end-systolic pressurevolume relation in conscious dogs to a wide range of contractile state. Circulation 1988;78:736-45.

38 Boltwood CM Jr, Appleyard RF, Glantz SA. Left ventricular volume measurement by conductance catheter in intact dogs: parallel conductance volume depends on left ventricular size. Circulation 1989;80:1360-77.

39 McKay RG, Miller MJ, Ferguson JJ, et al. Assessment of left ventricular end-systolic pressure-volume relations with an impedance catheter and transient inferior ven cava occlusion: use of this system in the evaluation of the cardiotonic effects of dobutamine, milrinone, posicor and 
epinephrine. J Am Coll Cardiol 1986;8:1152-60.

40 Kass DA, Yamazaki T, Burkhoff D, Maughan WL, Sagawa K. Determination of left ventricular end-systolic pressure-volume relationships by the conductance (volume) catheter technique. Circulation 1986;73:586-95.

41 Burkhoff $D$. The conductance method of left ventricular volume estimation: methodologic limitation put into perspective. Circulation 1990;81:703-6.

42 Iwase M, Sotobata I, Yokota M, et al. Evaluation of pulsed Doppler echocardiography of the atrial contribution to left ventricular filling in patients with DDD pacemakers. $A m$ Cardiol 1986;58:104-9.

43 Nitsch J, Seiderer M, Bull U, Luderitz B. Evaluation of left ventricular performance by radionuclide ventriculoventricular performance by radionuclide ventriculo-
graphy in patients with atrioventricular versus ventricular graphy in patients with atrioventricular versus ventric
demand pacemakers. Am Heart $J$ 1984;107:906-11.

44 Videen JS, Huang SK, Bazgan ID, Mechling E, Patton DD Hemodynamic comparison of ventricular pacing, atrioventricular sequential pacing, and atrial synchronous ventricular pacing using radionuclide ventriculography. Am J Cardiol 1986;57:1305-8.

45 Masuyama T, Kodama K, Nakatani S, Kitabatake A. Effects of atrioventricular interval on left ventricular diastolic filling assessed with pulsed Doppler echocardiography. Cardiovasc Res 1989;23:1034-42.

46 Wish M, Fletcher RD, Gottdiener JS, Cohen AI. Importance of left atrial timing in the programming of dualchamber pacemakers. Am J Cardiol 1987;60:566-71.

47 Naito M, Dreifus LS, David D, Michelson EL, Mardelli TJ, Kmetzo JJ. Reevaluation of the role of atrial systole to cardiac hemodynamics: evidence for pulmonary venous regurgitation during abnormal atrioventricular venous regurgitation during abnormal at
sequencing. Am Heart $J$ 1983;105:295-302.

48 Faerestrand $\mathrm{S}$, Oie $\mathrm{B}$, Ohm $\mathrm{O}$. Noninvasive assessment by
Doppler and $\mathrm{M}$-mode echocardiography of hemodynamic responses to temporary pacing and to ventriculoatrial conduction. PACE 1987;10:871-85.

49 Pepine CJ, Nichols WW, Conti CR. Aortic input impedance in heart failure. Circulation 1978;58:460-5.

50 Murgo JP, Westerhof N, Giolma JP, Altobelli SA. Aortic input impedance in normal man: relationship to pressure wave forms. Circulation 1980;62:105-16.

51 Burkhoff D, Alexander J Jr, Schipke J. Assessment of Windkessel as a model of aortic input impedance. $\mathrm{Am} \mathrm{J}$ Physiol 1988;255:H742-53.

52 Sunagawa K, Maughan WL, Sagawa K. Stroke volume effect of changing arterial input impedance over selected of changing arterial input impedance over selected

53 Sunagawa K, Sagawa K, Maughan WL. Ventricular interaction with the loading system. Ann Biomed Eng 1984; 12:163-89.

54 Rosenqvist $M$, Brandt J, Schuller $H$. Long-term pacing in sinus node disease: effects of stimulation mode on cardiovascular morbidity and mortality. Am Heart J 1988; 116:16-22.

55 Alpert MA, Curtis JJ, Sanfelippo JF, et al. Comparative survival following permanent ventricular and dualchamber pacing for patients with chronic symptomatic sinus node dysfunction with and without congestive heart failure. Am Heart J 1987;113:958-65.

56 BurkhoffD, Sagawa K. Ventricular efficiency predicted by an analytical model. Am J Physiol 1986;250:R1021-7.

57 Bedotto JB, Grayburn PA, Black WH, et al. Alterations in left ventricular relaxation during atrioventricular pacing in humans. J Am Coll Cardiol 1990;15:658-64.

58 Zile MR, Blaustein AS, Shimizu G, Gaasch WH. Right ventricular pacing reduces the rate of left ventricular relaxation and filling. J Am Coll Cardiol 1987;10:702-9. 